\title{
Global Ionospheric Radio Observatory (GIRO)
}

\author{
Bodo W. Reinisch ${ }^{1,2}$ and Ivan A. Galkin ${ }^{1}$ \\ ${ }^{1}$ University of Massachusetts Lowell, Center for Atmospheric Research, 600 Suffolk Street, Lowell, MA 01854 \\ ${ }^{2}$ Lowell Digisonde International, LLC, 175 Cabot Street, Lowell, MA 01854
}

(Received July 15, 2010; Revised March 2, 2011; Accepted March 3, 2011; Online published June 14, 2011)

\begin{abstract}
Digisonde ionospheric sounders installed at $80+$ locations in the world have gradually evolved their generally independent existence into a Global Ionospheric Radio Observatory (GIRO) portal. Today GIRO provides public access to $30+$ million records of ionospheric measurements collected at 64 locations, of which 42 provide realtime feeds, publishing their measurement data within several minutes from their completion. GIRO databases holding ionogram and Doppler skymap records of high-frequency ionospheric soundings have registered connections from 123 organizations in 33 countries. Easy access to the global state of the ionospheric plasma distribution given in accurate and fine detail by the ionosonde measurements has inspired a number of studies of the ionospheric response to space weather events. Availability of GIRO data with minimal latency allows for the assimilation of the ionogram-derived data in real-time models such as the real-time extension planned for the International Reference Ionosphere.
\end{abstract}

Key words: Digisonde network, ionospheric database, real-time IRI, GIRO.

\section{Introduction}

Accurate global modeling of Earth's ionosphere requires data from around the globe, and for a long time the data coverage has been inadequate. A quiet revolution in sensor network technologies started in the late 1990s with the advent of low-cost information technology solutions that permitted researchers and engineers to acquire, archive, and access their sensor data "without time or distance barriers" (NSF, 2003). Soon thereafter, a suite of virtual observatories $(\mathrm{VxO})$ started to emerge, with the task of registering a multitude of new data providers and their datasets in a uniform fashion under the framework of the SPASE metadata model (King et al., 2008). The new community of interoperable data providers has since then sustained its standalone operations at various host institutions, complementing the activities of the larger science data warehouses operated by governmental agencies, such as NASA and NSF in the United States, and international archives like the World Data Centers.

This revolution has significantly impacted the network of Digisonde ionospheric sounders (Reinisch et al., 2004) installed at $80+$ locations around the world which have gradually been evolving their generally independent existence into a Global Ionospheric Radio Observatory (GIRO) portal, http://giro.uml.edu. Today GIRO provides public access to $30+$ million records of ionospheric measurements collected at 64 locations, including 42 real time feeds (Fig. 1). All ionogram data from other digital ionosondes that use the SAO.XML archiving data format (Galkin et al., 2008a) can

Copyright (C) The Society of Geomagnetism and Earth, Planetary and Space Sciences (SGEPSS); The Seismological Society of Japan; The Volcanological Society of Japan; The Geodetic Society of Japan; The Japanese Society for Planetary Sciences; TERRAPUB.

doi:10.5047/eps.2011.03.001 be archived in the GIRO data depository.

Three main system developments have enabled the GIRO evolution: (1) database organization of the GIRO data at a central location with remote public access for both reading and writing; (2) custom software solutions that support GIRO operations in its multiple scenarios, ranging from expert ionogram interpretation to real time assimilation of ionogram-derived products, and that monitor the GIRO state of health; and (3) new installations of Digisonde-4D sounders (Reinisch et al., 2009), increasing the number of fielded instruments.

GIRO comprises three components: (1) the network of Digisonde stations providing online and offline data; (2) two master GIRO databases, the Digital Ionogram Data Base (DIDBase) and the DriftBase for skymap/drift measurements; and (3) associated software capable of automatic and interactive data analysis and the derivation of higher order data products for end user applications (Galkin et al., 2008b; Khmyrov et al., 2008; Kozlov and Paznukhov, 2008). The greatest operational impact has come through the single-point availability of the global network's realtime and retrospective data to both scientists and computer algorithms, free from handling tapes, cartridges, CDs, etc., a much-needed capability.

\section{Background: HF Sounding of the Ionosphere}

Ionograms (Fig. 2) are images of the ionosonde's radar returns that can be processed to provide an accurate "ground truth" knowledge of the bottomside vertical electron density profile (EDP) at the ionosonde location. The plasma frequency $\left(f_{\mathrm{p}}\right)$ profile (black line and uncertainty bars) from $90 \mathrm{~km}$ to the $F_{2}$ peak, derived from the vertical echo traces (e.g., Huang and Reinisch, 2001), is superimposed on the ionogram. The plasma frequency $f_{\mathrm{p}}$ is related to the elec- 


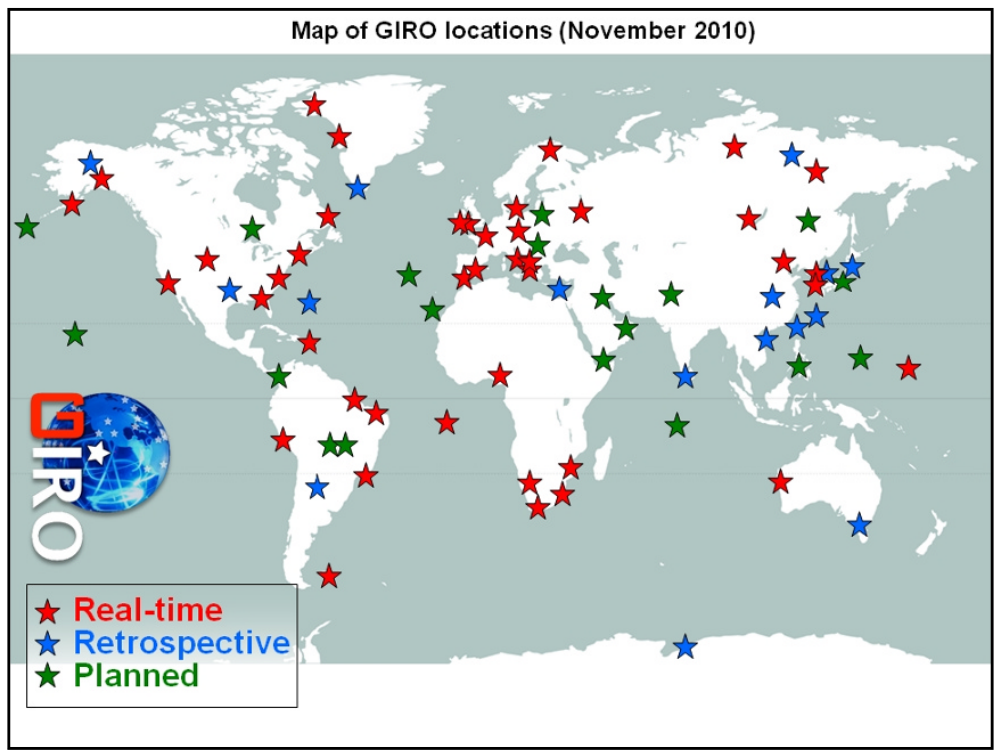

Fig. 1. Map of digisondes contributing data to GIRO. Red stars identify online digisondes providing data to GIRO in near-real-time, blue stars denote locations whose retrospective data collections are held in the GIRO archives, and green stars correspond to digisonde installations planned for 2011-2012.

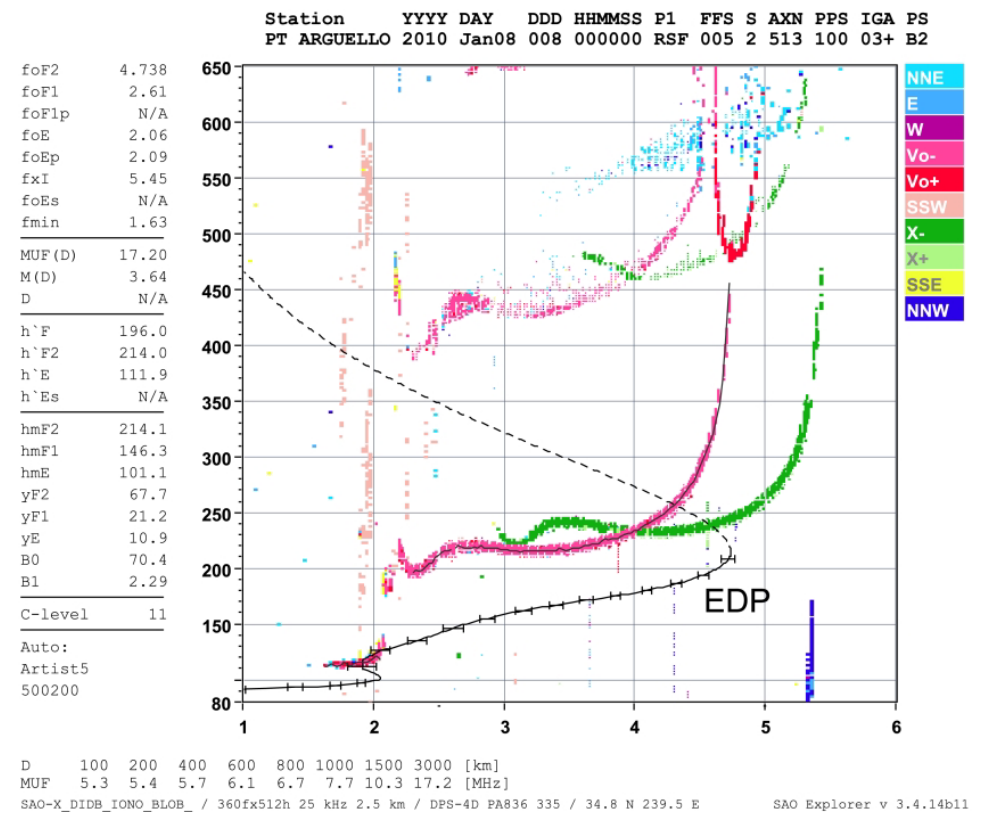

Fig. 2. Digisonde ionogram and the result of its automatic interpretation, including the EDP. Topside EDP section above the $F_{2}$ peak (dashed line) is obtained assuming an $\alpha$-Chapman shape of the profile. Red and green colors of echo points identify vertical $\mathrm{O}$ and $\mathrm{X}$ echoes with different shadings for positive and negative Doppler shifts. Echoes from NNE, E, W, SSE, and NNW have different colors.

tron density $N$ by $f_{\mathrm{p}} / 1 \mathrm{~Hz}=9 \sqrt{N / 1 \mathrm{~m}^{-3}}$. The topside portion of the profile above the $F_{2}$ peak (dashed line) is obtained assuming a simple $\alpha$-Chapman model of plasma distribution (Reinisch and Huang, 2001).

Extraction and interpretation of the signal traces in recorded ionogram images is an intelligent, machine-hard problem of feature recognition. The GIRO provides access to the Automatic Real-Time Ionogram Scaler with True height (ARTIST) software, an "autoscaler" of ionogram traces that uses the heritage of algorithm development going back to the 1980s (Reinisch and Huang, 1983; Galkin et al., 2008b). About $7 \%$ of available GIRO ionograms underwent a labor-intensive process of manually validating the autoscaling results. As of November 3, 2010 the DIDBase repository holds 733,516 records of expert-level manual ionogram scaling.

\section{GIRO Research Projects}

A prototype of the GIRO infrastructure was deployed in 2001 at the University of Massachusetts Lowell (UML) and, recognizing its utility in aiding ionospheric research, UML has continued its operation since then. The cornerstones of GIRO operations are the Digital Ionogram Data Base (DIDBase) with a Web portal ac- 
Millstone Hill Profilogram, November 6-8, 2004

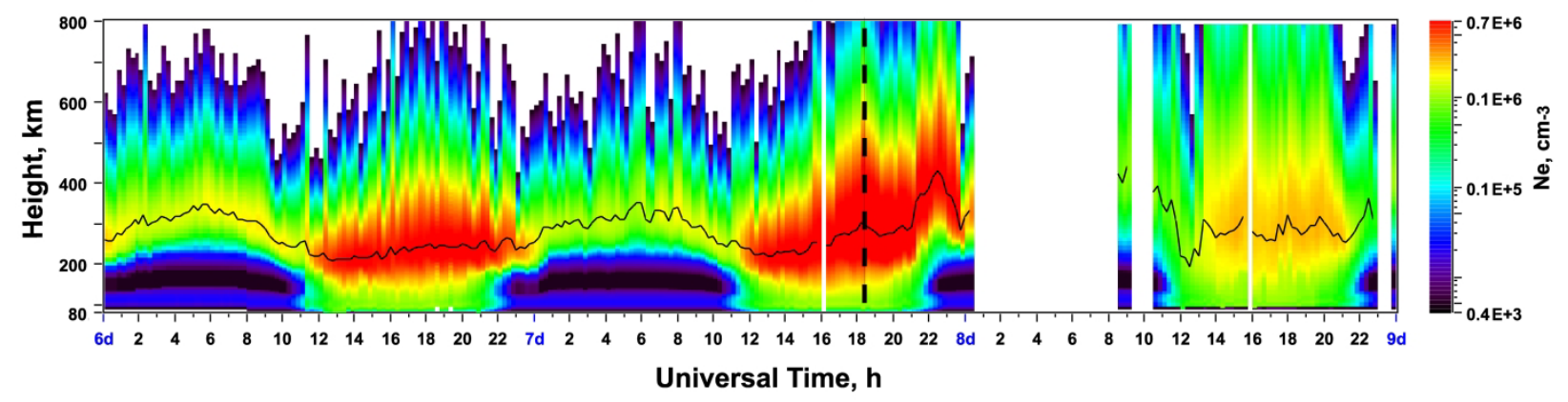

Fig. 3. The SAO Explorer profilogram plot of the electron density profiles at Millstone Hill, Massachusetts for 6-8 November 2004 shows the timeline of ionospheric response to an intense interplanetary shock event on 7 November 18:27 UT (dashed vertical line). Colors indicate the plasma density, and the black line marks the peak height $h_{\mathrm{m}} F_{2}$. Shortly after the shock event, the $F_{2}$ layer rose sharply in comparison to the previous day baseline. During the night on November 8 a severe 8 -hour absorption event blinded the instrument, while the densities during the daytime are markedly low (Zong et al., 2010).

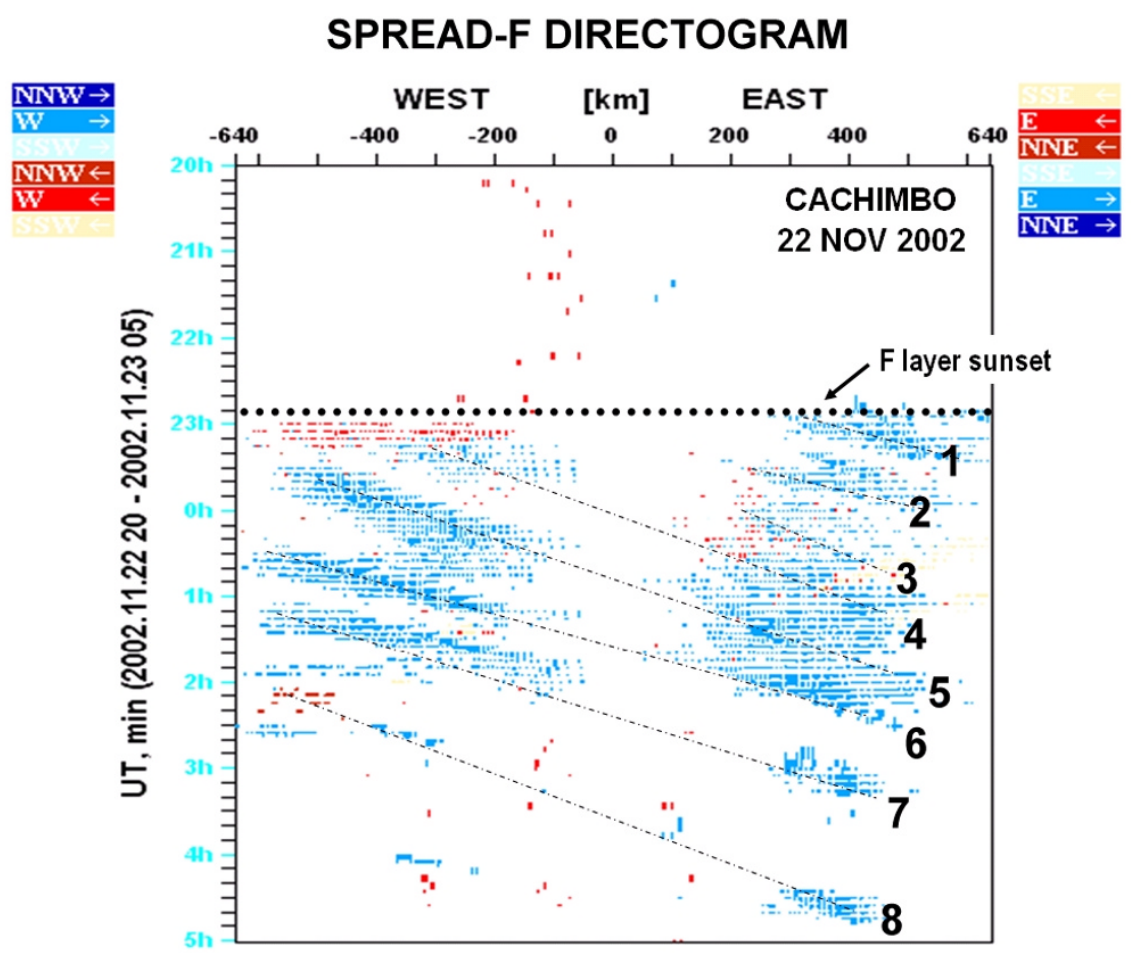

Fig. 4. Spread- $F$ directogram for Cachimbo, Brazil on 22-23 November 2002 showing the development of disturbed ionospheric conditions starting at $F$ layer sunset. The $y$-axis is universal time (LT $=\mathrm{UT}-3 \mathrm{~h}$ ); the $x$-axis is the horizontal distance to the reflectors in the west-east direction. Only off-vertical echoes are shown, and no vertical echoes are included in the plot. The directogram plot is optimized for equatorial locations, with blue colors for eastward and red colors for westward moving irregularities. The ionosphere is quiet until the day/night terminator passes at $22: 45$ UT; 8 plasma depletions are observed drifting eastward. The depletions labeled " 1 " and "2" formed east of the station. (courtesy M. Abdu and I. Batista, INPE)

cess at http://ulcar.uml.edu/DIDBase/, and the expert-level platform-independent software client "SAO Explorer" with $\mathrm{read} / \mathrm{write}$ access to DIDBase over the Internet. The first in-depth usage of the GIRO capability was made by the Aerospace Corporation, whose calibration and validation (CalVal) study (Paxton et al., 2002) of the UV instrumentation on DMSP satellites (Huffman, 1994) demanded accurate knowledge of the EDPs during the spacecraft passes over contributing GIRO locations. Orbit propagator software generated 20,524 coincidence time intervals for which manually validated EDPs were requested from the DID-
Base. This required the manual editing of 113,202 ionograms; i.e., four to five ionograms per station over-flight (over 5,000 man-hours!). The third CalVal campaign began in March 2010 and will continue to the end of 2011.

Easy access via GIRO to the globally distributed measurements of the ionospheric plasma has also inspired a number of studies of the ionospheric response to space weather events (e.g., Abdu et al., 2008; Lei et al., 2008; Paznukhov et al., 2009; Zong et al., 2010; Stanislawska et al., 2010). 


\section{Real-time GIRO Applications}

Use of real-time ARTIST-derived data as input to ionospheric models and associated algorithms such as ray tracing and optimal frequency allocation started in 1988 when the USAF Weather Agency (AFWA) established a network of 18 Digisondes (Buchau et al., 1995). The real-time data streams from these instruments were provided for assimilation into ICED/PRISM (Daniell et al., 1990, 1993) and later to GAIM (Schunk et al., 2004; Scherliess et al., 2006). Since then, other agencies have built similar networks: the Digital Atmospheric Server (DIAS) (Belehaki et al., 2005) became operational in 2004 with 6 contributing Digisondes located in Europe; and the Jindalee Operational Radar Network of the Australian government installed 11 Digisondes (Gardiner-Garden, 2006) to provide data to their real time ionospheric model RTIM (Wheadon et al., 1994; Barnes et al., 2000). GIRO data have also been used to update the Boeing Plasma Interaction Model (PIM) (Barsamian et al., 2003) in support of spacewalk scheduling for the International Space Station.

\section{Public Access to GIRO Repositories}

In 1997, the embedded computers in the Digisonde ionospheric sounders started web-publishing three data products: the latest ionogram measurement image, the 2-week history of ionogram measurements, and the complete historic record of ionogram-derived autoscaled data at a station. The original enthusiasm of the 1990s, however, wore off a decade later because of concerns that exposure to the hazards of the internet may compromise the instruments. A growing number of Digisondes closed their site to direct access, and instead the web portal became a new paradigm of centralized management of the Digisonde data. Such a portal can provide one-stop access to all Digisonde-related functions, including data visualization and expert ionogram interpretation using the interactive SAO Explorer and Drift Explorer tools (Khmyrov et al., 2008; Kozlov and Paznukhov, 2008). The GIRO Web Portal, http://giro.uml.edu/, provides a common point for data providers (62 locations in 27 countries) and data users (123 organizations with 153 read-only and 34 expert readwrite accounts). Increasing attention is drawn to the latest ionogram images from contributing stations, including 24-hour up-to-date composite GIRO ionogram movies at http://giro.uml.edu/IonogramMovies/.

While the GIRO Web Portal solves a number of everyday tasks that require knowledge of the latest ionograms around the world, expert-level processing and visualization of the data is done with the SAO Explorer and Drift Explorer software applications connected to the GIRO databases. Examples are shown in Figs. 3 and 4. The "profilogram" image in Fig. 3 displays the EDPs for three days, derived from the Millstone Hill ionograms. Another example of advanced data visualization by SAO Explorer is the spread $F$ "directogram" (Fig. 4) which plots the oblique echo locations measured in the ionogram to detect and track the plasma irregularities/depletions responsible for the onset of spread $F$. Only the non-vertical echoes in the ionogram are retained for these plots.

The GIRO contributors and its host organizations strictly follow the scientific data sharing principles by providing all Digisonde data to academic and other research organizations free of charge for their ionospheric studies. All GIRO data users are advised to respect the rights of contributors on their expert-level work to explore, discover, and interpret data. Given the high expense of the efforts involved in the expert ionogram analysis, all manually derived data products are attributed the status of "intellectual property" by preserving the proprietor name, submission date, and optional descriptive messages in the GIRO databases. It is expected that publications using manually validated data retrieved from the GIRO archives include the data proprietor as a co-author. Use of the raw data and automaticallyderived secondary GIRO products requires at least a formal acknowledgement of the contributing Digisonde owner organizations and the GIRO development team in published material.

\section{Future Development}

Recently, the International Reference Ionosphere (IRI) science team started developing a real-time IRI extension that will depend on GIRO streams. By design, IRI belongs to a class of empirical models (Bilitza, 2001, 2004, 2009) that represent direct ionospheric measurements, thus avoiding the uncertainties of the evolving theoretical understanding of ionospheric processes and their coupling to processes in the magnetosphere, interplanetary space, and lower atmosphere. As such, IRI captures very well the prominent features of the plasma behavior, such as the day/night changeover, the Appleton anomaly, and seasonal climatology that persists over long periods of time. While the IRI model is often anecdotally portrayed as the "best" ionospheric background model, it has had only limited success in representing ionospheric responses to various short-term events, observed during periods of storm activity (Araujo et $a l ., 2005)$ or the impact of gravity waves coupling the ionosphere to the lower atmosphere. Ingestion of real time GIRO and other data into IRI is now being considered with the aim of "updating" the IRI electron density distribution while preserving the overall integrity of its representation of typical ionospheric features.

An initial approach to the IRI assimilation task could be for GIRO to determine an "effective" solar activity index $\left(R_{12}\right)$ value as a function of time to be used instead of the predicted $R_{12}$ value for the month of interest. The index $R_{12}$ is the only independent parameter in IRI and can be manipulated to minimize the cumulative discrepancy between the model and available observations similar to the methods reported by Hernandez et al. (2002) and Zolesi et al. (2004). Such single parameter approach will likely not be fully satisfactory for global coverage of the model. It will be better to expand the assimilation algorithm by evaluating and minimizing varying global differences between model and observations, rather than assuming a constant bias. Using the capability of the GIRO to store sensor measurements in the database, the assimilation algorithm would analyze the latest 24-hour history of differences between the IRI prediction and the ionogram-derived characteristics to mitigate those differences. The Galileo correction model is based on similar techniques (e.g., Rogers et al., 2005). 


\section{Conclusions}

GIRO provides a one-point access to a global network of digital ionosondes many of which feed their data in real time to the GIRO data depositories. The steadily increasing use of DIDBase and DriftBase by scientists, engineers, students, and radio amateurs across the globe, especially from developing countries, suggests that the GIRO Portal is a desirable service to the ionosphere and space weather community.

Acknowledgments. The initial DIDBase repository was established with support from the USAF Research Laboratory through contract \# F19628-02-C-0092. The authors acknowledge Digisonde owner organizations and international ionogram scaling teams for their good will in continuing uploads of their data to GIRO for public dissemination.

\section{References}

Abdu, M. A. A., E. R. de Paula, I. S. Batista, B. W. Reinisch, M. Matsuoka, P. Camargo, O. Veliz, C. M. Denardini, J. H. A. Sobral, E. A. Kherani, and P. Sequeira, Abnormal evening vertical plasma drift and effects on ESF and EIA over Brazil-South Atlantic sector during the October 30, 2003 super-storm, J. Geophys. Res., 113(A7), A07313, doi:10.1029/2007JA012844, 2008.

Araujo-Pradere, E. A., T. J. Fuller-Rowell, M. V. Codrescu, and D. Bilitza, Characteristics of the ionospheric variability as a function of season, latitude, local time, and geomagnetic activity, Radio Sci., 40, RS 5009, doi:10.1029/2004RS003179, 2005.

Barnes, R. I., R. S. Gardiner-Garden, and T. J. Harris, Real time ionospheric models for the Australian Defence Force, Proc. WARS-2000, 122-135, 2000.

Barsamian, H., R. Mikatarian, J. Alred, J. Minnow, and S. Koontz, ISS Plasma Interaction: Measurements and modeling, 8th Spacecraft Charging Technology Conference, Huntsville, AL, 2003.

Belehaki, A., L. Cander, B. Zolesi et al., DIAS project: The establishment of a European digital upper atmosphere server, J. Atmos. Sol.-Terr. Phys., 1092-1099, 2005.

Bilitza, D., International Reference Ionosphere 2000, Radio Sci., 36(2), 261-275, 2001, 2001.

Bilitza, D., A correction for the IRI topside electron density model based on Alouette/ISIS topside sounder data, Adv. Space Res., 33(\#6), 838843, 2004.

Bilitza, D., Evaluation of the IRI-2007 model options for the topside electron density, Adv. Space Res., 44(\#6), 701-706, doi:10. 1016/j.asr.2009.04.036, 2009.

Buchau, J., T. W. Bullett, A. E. Ronn, K. D. Scro, and J. L. Carson, The Digital Ionospheric Sounding System network of the US Air Force Weather Service, WDC-A for Solar-Terr. Phys., Report UAG-104, pp. 16-20, 1995.

Daniell, R. E., D. T. Decker, D. N. Anderson, J. R. Jaspers, J. J. Sojka, and R. W. Schunk, A Global Ionospheric Conductivity and Electron Density (ICED) Model, in Proceedings of the Ionospheric Effects Symposium, edited by J. M. Goodman, 1-3 May 1990, 1990.

Daniell, R. E., W. G. Whartenby, and L. D. Brown, Parameterised Real Time Ionospheric Specification Model, PRISM version 1.2, Computational Physics, Inc., 385 Elliot St, Newton, MA 02164, USA, 1993.

Galkin, I. A., G. M. Khmyrov, A. V. Kozlov, B. W. Reinisch, X. Huang, and V. V. Paznukhov, The ARTIST 5, in Radio Sounding and Plasma Physics, AIP Conf. Proc., 974, 150-159, 2008a.

Galkin, I. A., G. M. Khmyrov, B. W. Reinisch, and J. McElroy, The SAOXML 5: New format for ionogram-derived data, Radio Sounding and Plasma Physics, AIP Proceedings, 974, 160-166, 2008b.

Gardiner-Garden, R. S., Ionospheric variability in sounding data from JORN, Proc. WARS 2006, Leura, NSW, Australia, 2006.

Hernandez-Pajares, M., J. Juan, J. Sanz, and D. Bilitza, Combining GPS measurements and IRI model values for space weather specification, Adv. Space Res., 29(6), 949-958, 2002.
Huang, X. and B. W. Reinisch, Vertical electron content from ionograms in real time, Radio Sci., 36, 335-342, 2001.

Huffman, R. E., Recent advances in atmospheric ultraviolet remote sensing, Ultraviolet Technology V, Proc. SPIE, 2282, 138-144, 1994.

Khmyrov, G. M., I. A. Galkin, A. V. Kozlov, B. W. Reinisch, J. McElroy, and C. Dozois, Exploring digisonde ionogram data with SAO-X and DIDBase, in Radio Sounding and Plasma Physics, AIP Conf. Proc., 974, 175-185, 2008.

King, T., J. Merka, R. Walker, S. Joy, and T. Narock, The architecture of a multi-tiered virtual observatory, Earth Sci. Inf., 1, doi: 10.1007/s12145008-0006-3, 2008.

Kozlov, A. and V. V. Paznukhov, Digisonde drift analysis software, in Radio Sounding and Plasma Physics, AIP Conf. Proc., 974, 167-174, 2008.

Lei, J., W. Wang, A. G. Burns, S. C. Solomon, A. D. Richmond, M. Wiltberger, L. P. Goncharenko, A. Coster, and B. W. Reinisch, Observations and simulations of the ionospheric and thermospheric response to the December 2006 geomagnetic storm: Initial phase, J. Geophys. Res., 113(A1), A01314, doi:10.1029/2007JA012807, 2008.

NSF Program Solicitation 03-512, Sensors and Sensor Networks, March 2003, 2003.

Paxton, L. J., D. Morrison, Y. Zhang, H. Kil, B. Wolven, B. S. Ogorzalek, D. C. Humm, and C.-I. Meng, Validation of remote sensing products produced by the Special Sensor Ultraviolet Scanning Imager (SSUSI): a far UV-imaging spectrograph on DMSP F-16, Proc. SPIE, 4485, 338348, 2002.

Paznukhov, V. V., D. Altadill, and B. W. Reinisch, Experimental evidence for the role of the neutral wind in the development of ionospheric storms in midlatitudes, J. Geophys. Res., 114, A12319, doi:10.1029/2009JA014479, 2009.

Reinisch, B. W. and X. Huang, Automatic calculation of electron density profiles from digital ionograms, 3, Processing of bottomside ionograms, Radio Sci., 18, 477-492, 1983.

Reinisch, B. W. and X. Huang, Deducing topside profiles and total electron content from bottomside ionograms, Adv. Space Res., 27, 23-30, 2001.

Reinisch, B. W., I. A. Galkin, G. Khmyrov, A. Kozlov, and D. F. Kitrosser, Automated collection and dissemination of ionospheric data from the digisonde network, Adv. Radio Sci., 2, 241-247, 2004.

Reinisch, B. W., I. A. Galkin, G. M. Khmyrov et al., The new digisonde for research and monitoring applications, Radio Sci., 44:p RS0A24, doi:10.1029/2008RS004115, 2009.

Rogers, N., J. E. N. Field, P. S. Cannon, and M. J. Angling, An assessment of the Galileo single-frequency ionospheric correction model, www. ursi.org/Proceedings/ProcGA05/pdf/GP1G02.6(01296).pdf, 2005.

Scherliess, L., R. W. Schunk, J. J. Sojka, D. C. Thompson, and L. Zhu, Utah State University Global Assimilation of Ionospheric Measurements Gauss-Markov Kalman filter model of the ionosphere: Model description and validation, J. Geophys. Res., 111, A11315, doi:10. 1029/2006JA011712, 2006.

Schunk, R. W., L. Scherliess, J. J. Sojka, and D. Thompson, Global Assimilation of Ionospheric Measurements (GAIM), Radio Sci., 39, RS1S02, doi:10.1029/2002RS002794, 2004.

Stanislawska, I., J. Lastovicka, A. Bourdillon, B. Zolesi, and Lj. R. Cander, Monitoring and modeling of ionospheric characteristics in the framework of European COST 296 Action MIERS, Space Weather, 8(2), S02001, doi:10.1029/2009SW000493, 2010.

Wheadon, N. S., J. C. Whitehouse, J. D. Milsom, and R. N. Herring, Ionospheric Modeling and Target Coordinate Registration for HF Skywave radars, HF Radio Systems and Techniques, No 392, 4-7, 1994.

Zolesi, B., A. Belehaki, I. Tsagouri, and L. Cander, Real-time updating of the Simplified Ionospheric Regional Model for operational applications, Radio Sci., 39(2), RS2011, 10.1029/2003RS002936, 2004.

Zong, Q.-G., B. W. Reinisch, P. Song, Y. Wei, and I. Galkin, Dayside ionospheric response to the intense interplanetary shocks/solar wind discontinuities: Observations from the digisonde global ionospheric radio observatory, J. Geophys. Res., 115, A06304, doi:10.1029/2009JA014796, 2010 .

B. W. Reinisch (e-mail: Bodo_Reinisch@uml.edu) and I. A. Galkin 